\title{
Squamous cell carcinoma of the vulva in a virgin patient with Turner syndrome
}

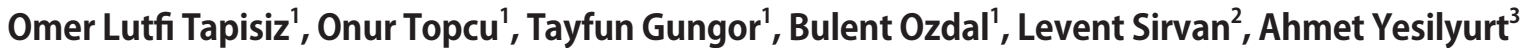

Departments of ${ }^{1}$ Gynecologic Oncology, ${ }^{2}$ Pathology, and ${ }^{3}$ Genetics, Dr. Zekai Tahir Burak Women's Health Education and Research Hospital, Ankara, Turkey

Two types of gynecologic tumors are commonly described in the Turner syndrome, the first one is gonadoblastoma, which occurs in patients with $Y$ chromosome abnormalities, and the second one is endometrial carcinoma which is mostly related with exogenous estrogen usage. Here, we describe an extremely rare case of squamous cell carcinoma of the vulva in a virgin woman with Turner syndrome. A 35-years old single, virgin woman referred to our Oncology Department with warty, necrotized, exophytic 6-7 cm vulvar mass. She had a history of primary amenorrhea and mosaic Turner syndrome was determined in her karyotype analysis. Biopsy specimen of the vulvar mass revealed squamous cell carcinoma of the vulva, and total vulvectomy with inguinal femoral lymphadenectomy was performed. The postoperative course was uneventful and there has been no recurrence of the disease up to date. Women with Turner syndrome have streak ovaries that produce very low estrogen and the squamous cell carcinoma of the vulva may have developed at an early age with Turner syndrome because of this low estrogen value similar to postmenopausal women. The current case is a special case due to its age of occurrence, virgin and Turner syndrome status.

Keywords: Squamous cell carcinoma, Turner syndrome, Virgin, Vulvar carcinoma

\section{INTRODUCTION}

Turner syndrome (TS) is the most common chromosomal abnormality in females, affecting $1: 2,500$ live female births, and is a condition involving total or partial absence of one $X$ chromosome in all or part of the cells, reduced final height, absence of female sex hormones, and in most cases infertility [1]. Some cancer types, such as colon cancer, thyroid carcinoma, and acute myeloid leukemia were reported in patients with TS [1-3]. Two types of gynecologic tumors are commonly

Received Aug 15, 2010, Accepted Oct 6, 2010

Correspondence to Omer Lutfi Tapisiz

Department of Gynecologic Oncology, Dr. Zekai Tahir Burak Women's Health Education and Research Hospital, Turan Gunes Bulvari, Sedir Sitesi, C2 Blok, No:6, Oran, Ankara 06450, Turkey. Tel: 90-505-319-7577, Fax: 90312-312-4931,E-mail: omertapisiz@yahoo.com.tr described in TS, the first one is gonadoblastoma, which occurs in patients with $Y$ chromosome abnormalities, and the second one is endometrial carcinoma which is mostly related with exogenous estrogen usage $[1,4]$. Here, we describe an extremely rare case of squamous cell carcinoma of the vulva (SCCV) in a young virgin woman with Turner syndrome.

\section{CASE REPORT}

A 35-years old single, virgin woman referred to our Oncology Department with wart like, necrotized, exophytic vulvar mass. The size of the lesion was around 6-7 cm. It was originated from the left labia majora and extended to the clitoris and urethral meatus. There was a suspicious palpable right groin lymph node. Biopsy specimen of the vulvar mass revealed SCCV (well-differentiated). 


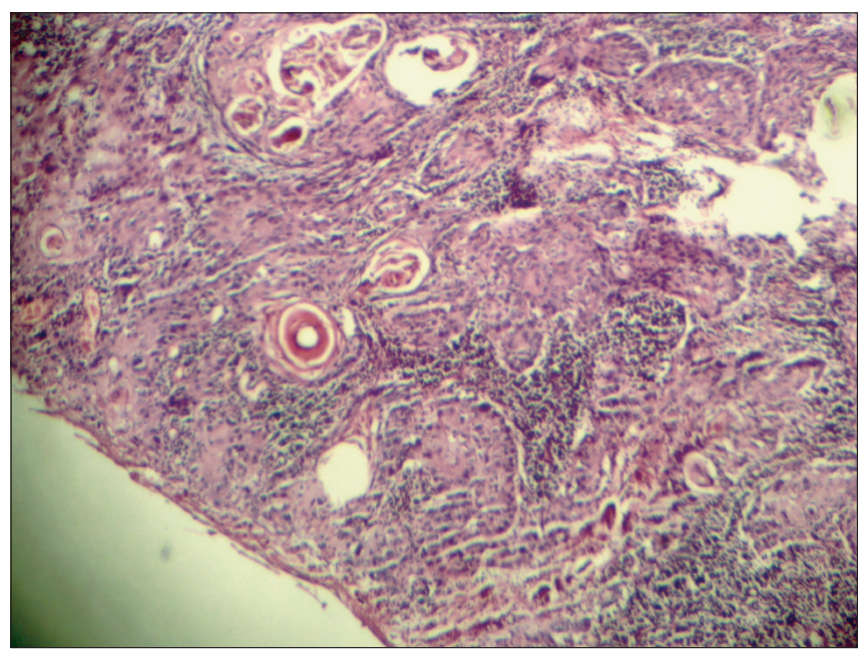

Fig. 1. Microscopic finding of the patient; squamous cell carcinoma of the vulva, tumoral cell groups infiltrate the stroma irregularly $(H \& E, X$ 100).

She had a history of primary amenorrhea, and the clinical diagnosis of TS before but she did not have the medical reports proving TS. Therefore, karyotype analysis was performed in our hospital's Genetic Department by the conventional Gbanding method using peripheral blood lymphocytes. Mosaic TS was determined in her karyotype analysis. According to her history, she had no sexual relationship of any kind. She had received estrogen replacement therapy for only 6 months, and she had no history of tobacco use. Her family history was unremarkable. The serum hormonal assay revealed, FSH, 64.86 $\mathrm{mIU} / \mathrm{mL}$; LH, $38.45 \mathrm{mIU} / \mathrm{mL}$; progesterone, $0.38 \mathrm{pg} / \mathrm{mL}$; and estradiol, $14.54 \mathrm{pg} / \mathrm{mL}$, all of the other laboratory results were normal.

Total vulvectomy with inguinal femoral lymphadenectomy was performed. The final histological diagnosis was SCCV (Fig. 1), and vascular or neuronal invasion was not observed. The surgical margins were free of disease. The inguinal and femoral lymph nodes were negative. The clinicopathologic stage (FIGO) was stage II. The postoperative course was uneventful and there has been no recurrence of the disease up to date.

\section{DISCUSSION}

Cancer of the vulva which is primarily a disease of postmenopausal women, with a peak incidence in the late 60 's is responsible for approximately 3-5\% of gynecologic cancers. SCCV is the most common type among the vulvar cancers. This disease typically develops in older women (in their seventh or eighth decade of life) and is rarely seen in women younger than 35 years of age [5]. The current case is a special case due to its age of occurrence, virgin and TS status. To our knowledge, there are no published reports of SCCV in a young virgin woman with TS.

The etiology of SCCV is not well known and epidemiological evidence to date suggests that there are two etiologic pathways responsible in carcinogenesis [6,7]. The first one is often seen in older women and related with non-neoplastic epithelial disorders, mainly atrophic dystrophy which is seen in low estrogen states. The second one is often seen in younger women and is associated with human papillomavirus (HPV) infection [8]. The study performed by Jones et al. suggested an increasing incidence of vulvar intraepithelial neoplasm related with HPV in women younger than 50 years of age [9]. Another study reported by Huang et al. [10] showed the importance of HPV integration in both cervical and vulvar cancers. However; both of the etiologic paths were not appropriate for explaining the mechanism of the disease in our young and virgin case. Other risk factors include current tobacco use, the presence of genital warts, and multiple sexual partners $[7,8]$, but these were also not present in our case.

In the English literature, we found only one case that presented with vulvar carcinoma in a TS patient. In this report Iwamoto et al. [11] concluded that the vulvar carcinoma may be related with low estrogen levels in TS like in elderly postmenopausal women. In our opinion this etiologic path may explain our cases' condition.

In conclusion, women with TS have streak ovaries that produce very low estrogen and SCCV may have developed at an early age with TS because of this low estrogen value similar to postmenopausal women. Here, we described the first case of SCCV in a young virgin patient with TS.

\section{CONFLICT OF INTEREST}

No potential conflict of interest relevant to this article was reported.

\section{REFERENCES}

1. Elsheikh M, Dunger DB, Conway GS, Wass JA. Turner's syndrome in adulthood. Endocr Rev 2002;23:120-40.

2. Chaganti RS, Bailey RB, Jhanwar SC, Arlin ZA, Clarkson $\mathrm{BD}$. Chronic myelogenous leukemia in the monosomic cell line of a fertile Turner syndrome mosaic $(45, X / 46, X X)$. Cancer Genet Cytogenet 1982;5:215-21.

3. Cabanas P, Garcia-Caballero T, Barreiro J, Castro-Feijoo 
L, Gallego R, Arevalo T, et al. Papillary thyroid carcinoma after recombinant GH therapy for Turner syndrome. Eur J Endocrinol 2005;153:499-502.

4. Sybert VP, McCauley E. Turner's syndrome. N Engl J Med 2004;351:1227-38.

5. Gadducci A, Cionini L, Romanini A, Fanucchi A, Genazzani AR. Old and new perspectives in the management of high-risk, locally advanced or recurrent, and metastatic vulvar cancer. Crit Rev Oncol Hematol 2006;60:227-41.

6. Madeleine MM, Daling JR, Carter JJ, Wipf GC, Schwartz SM, McKnight B, et al. Cofactors with human papillomavirus in a population-based study of vulvar cancer. J Natl Cancer Inst 1997:89:1516-23.

7. Canavan TP, Cohen D. Vulvar cancer. Am Fam Physician 2002;66:1269-74.
8. Stroup AM, Harlan LC, Trimble EL. Demographic, clinical, and treatment trends among women diagnosed with vulvar cancer in the United States. Gynecol Oncol 2008; 108:577-83.

9. Jones RW, Baranyai J, Stables S. Trends in squamous cell carcinoma of the vulva: the influence of vulvar intraepithelial neoplasia. Obstet Gynecol 1997;90:448-52.

10. Huang FY, Kwok YK, Lau ET, Tang MH, Ng TY, Ngan HY. Genetic abnormalities and HPV status in cervical and vulvar squamous cell carcinomas. Cancer Genet Cytogenet 2005; 157:42-8.

11. Iwamoto I, Kijima Y, Fujino T, Yoshinaga M, Douchi T. Verrucous carcinoma of the vulva in Turner syndrome. Gynecol Oncol 2004;92:380-3. 